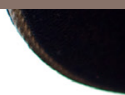

U RE G I N A

V USASK

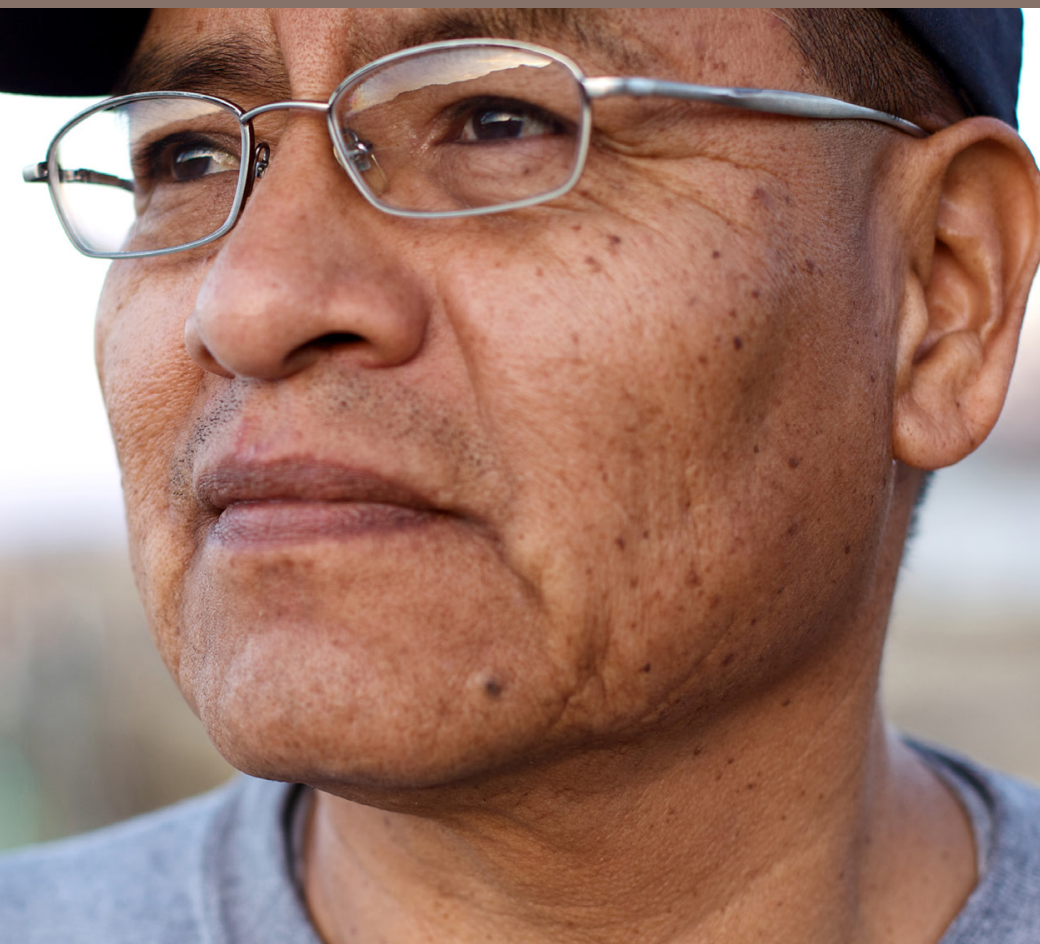

PHOTO CREDIT: ISTOCK BY GETTY IMAGES

\title{
No Easy Answers: Insights into Community Well-being among First Nations
}

John Richards, Professor, Simon Fraser University School of Public Policy, and Roger Phillips Chair in Social Policy, C.D. Howe Institute

June 2, 2020

[This is a précis of a longer monograph recently published by the C.D. Howe Institute. It is freely available at www.cdhowe.org]

Since 1981, Ottawa has published the Community Well-Being Index (CWB), an exercise in rating social conditions in individual First Nation and Inuit communities. The CWB is constructed from four equally weighted sub-indices: per capita community income, an education index, a labour-force participation index, and a housing index. CWB calculations come from the most recent Census data. In order to compare with mainstream Canadian communities, it includes equivalent results for "other" communities across Canada.

The first goal of this Policy Brief is to summarize the latest CWB data, based on the 2016 Census. The second is to make the case that low employment among many First Nation communities deserves far more policy attention than it receives. The problems arising from low employment are particularly acute in the Prairies.

At least since the 1996 report of the Royal Commission on Aboriginal Peoples, the dominant agenda among Indigenous and nonIndigenous political leaders, among academics, and among policy analysts has been rehabilitation of First Nation cultures via expansion of treaty rights. To quote the report: "Canadians need to understand that Aboriginal peoples are nations [emphasis in original] ... To this day, Aboriginal people's sense of confidence and well-being remains tied to the strength of their nations. Only as members of restored nations can they reach their potential in the twenty-first century. (Canada 1996, x-xi.)

This is a valuable agenda. However, if it implies that those identifying as First Nations cannot "reach their potential" while living in cities, and that closing socio-economic gaps between First Nation and other communities can be subsumed under strategies designed to affirm treaty rights, it is a limiting agenda. Average CWB scores for First Nations have modestly increased since 1981, but many sub-indices are stagnant.

Statistics Canada provides the Census data from which Indigenous Services Canada has constructed 2016 CWB scores for 623 First Nation communities, 50 Inuit communities, and 3,781 "others" (ranging from Toronto, Montreal, and Vancouver to small towns). Figure 1 illustrates, for First Nation communities, average regional scores on three subindices and a redefined regional employment rate. There are several 
summary points to make:

- From the first CWB index in 1981 to 2016, the average First Nation score has risen from 45.0 to 58.4 , the Inuit score from 46.1 to 61.3 , and the non-Indigenous score from 64.5 to 77.5 . (Scores range from 0 - 100.) All three scores have risen, but the gaps between non-Indigenous on the one hand, and either First Nation or Inuit have remained nearly constant.

- The First Nation labour-force score incorporated in the CWB distributions combines labour force participation rate and employment rate. The latter is defined in a manner significantly different from that used by Statistics Canada. In Figure 1, the CWB labour-force score has been replaced with regional employment rates, defined in a manner similar to that in the Census.'

- There exists overlap among the three distributions-but not much. Coincidentally, 71 is the top decile CWB score for the First Nation and Inuit communities, and the bottom decile for the "other" communities. In other words, nine of 10 First Nation and Inuit communities score below 71 ; nine of 10 of the "other" communities score more than 71.

- At a regional level, the most severe social outcomes, as measured by the CWB sub-indices, are in the three Prairie provinces, which collectively account for 45 percent of the population living in a First Nation community.

- In Manitoba and Saskatchewan, average community income scores are 10 points lower than the Canadian average_-and roughly 15 points lower than in Quebec and British Columbia.

Figure 1: CWB Sub-Index Scores and Revised Employment Rate, First Nation Communities, Canada and Regions, 2016

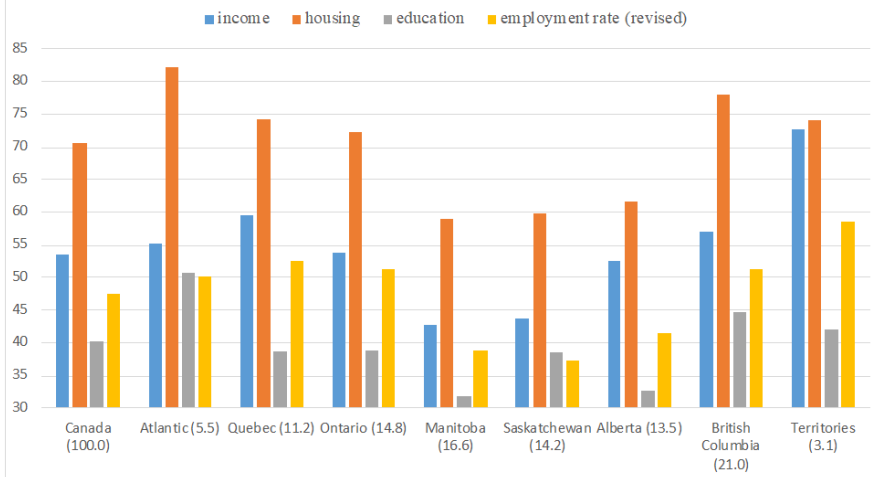

Source: Author's calculations from Canada (2019).

Note: Numbers in parentheses indicate the regional distribution, by percentage, of the First Nation population included in the CWB. Total First Nation populatio included is 394,000 .

\section{Employment Matters}

There is a long tradition in social policy that emphasizes the role of employment-young adult male employment in particular-as a key determinant of social outcomes in a community. Several motivations are behind the emphasis on employment:

- In general, two-parent families realize better outcomes for children and for themselves than do one-parent alternatives.
In any community, women, when choosing marriage partners, use employment as a proxy for men's suitability as fathers. In marginalized communities, where many young men experience a low employment rate, young women often seek second-best alternatives (such as grandmothers as prime caregivers) for raising children (Wilson 1996; Murray 2012).

- Adverse employment conditions are particularly damaging for men with low education levels. During the last quarter century in the US and most other high-income countries, men with high school or less have disproportionately experienced employment and income declines and above-average prevalence of many pathologies (Autor et al. 2018).

- Those not in education, employment, or training are by definition the NEET population. In the cohort ages 20-29, adults typically form unions and begin families. The NEET subset of this cohort is less likely to form stable unions than the non-NEET. The Indigenous NEET rate among the cohort ages 20-24 is approximately twice that for the total Canadian population. This group is less likely to participate actively in raising children that arise from a union, and is prone to depression and abuse of alcohol and drugs (Putnam 2015; Brunet 2019; Case and Deaton 2020).

As summarized above, the emphasis on employment may seem reductive. There is, nonetheless, extensive evidence that the "employment thesis" is crucial to understanding intergenerational poverty in high-income countries. There is no reason to think First Nation communities are exempt from these dynamics. To acknowledge the dire effects of low employment in many First Nation communities does not deny the destructive historical legacy of discrimination toward the Indigenous population. It does, however, imply a higher priority to address low employment.

William Julius Wilson, a prominent American sociologist, developed his ideas on the role of employment in family formation primarily in the context of American inner-city ghettos. Writing in 1996, he summarized:

The disappearance of work and the consequences of that disappearance for both social and cultural life are the central problems in the inner-city ghetto. To acknowledge that the ghetto still includes working people and that nearly all ghetto residents, whether employed or not, support the norms of the work ethic ... should not lead one to overlook the fact that a majority of adults in many inner-city neighborhoods are jobless at any given point in time. (Wilson 1996, xix.)

Case and Deaton (2020) have analyzed, among cohorts of Americans born since 1940, the prevalence trends of numerous morbidities and sources of distress: suicide, chronic joint pain, difficulty in socializing, heavy drinking, mental distress, sciatic pain, drug/alcohol mortality, not married, never married, not in the labour force. The authors make no claim to have the definitive explanation for these trends. However, they introduce evidence on the importance of declines in wages and in labour force participation among white working-class Americans with education levels below a bachelor's degree. 
No studies as rigorous as those conducted in low-employment US communities have been undertaken among the Indigenous population in Canada, but there exists abundant cross-section evidence to the effect that First Nation communities with low employment rates experience higher social dysfunction. For example, Statistics Canada (Beattie et al. 2018) regularly publishes data on homicide statistics in Canada, disaggregated in terms of Indigenous/non-Indigenous identity, gender, and province. ${ }^{2}$ In 2017, the national Indigenous share of total homicide victims stood at one-quarter; the Indigenous share of those accused of homicide stood above one-third. Nationally, these rates are approximately six times the comparable gender-specific non-Indigenous rates. Men comprise three-quarters of both Indigenous victims of homicide and Indigenous perpetrators. A disproportionately large share of Indigenous victims and indigenous perpetrators of homicides (two-thirds in both categories) take place in the Prairie provinces, the regions with lowest employment. The memoirs of Harold Johnson (2016), long-time Crown prosecutor in northern Saskatchewan, provide a harrowing account of social problems in First Nation communities. He emphasizes the problems arising from alcohol.

Figure 2: Employment Rate (revised), First Nation Communities, Canada and Regions, 1981-2016

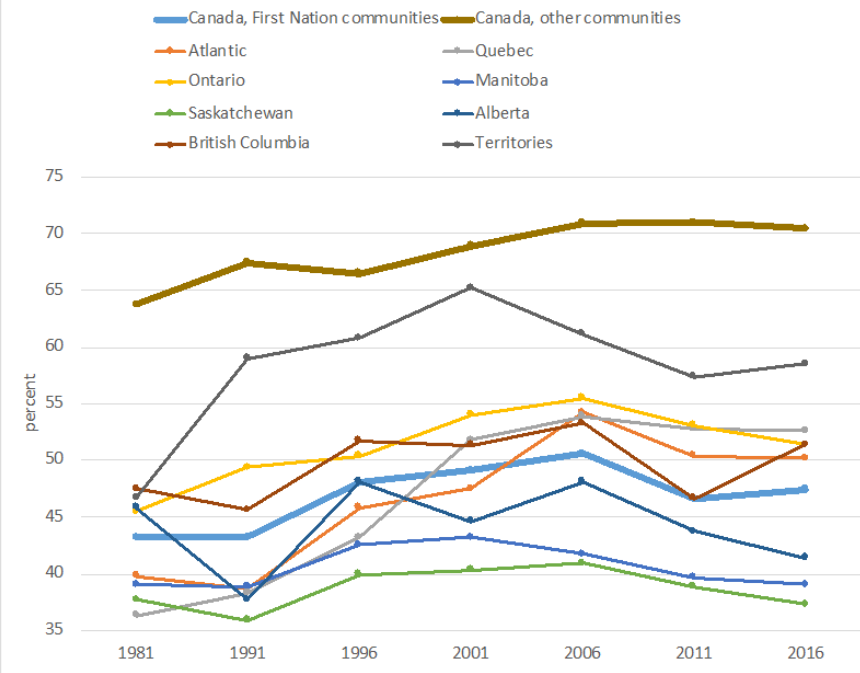

Source: Author's calculations from Canada (2019).

Using the revised employment rate definition, Figure 2 provides an overview of national and regional 1981-2016 employment trends among First Nation and "other" communities). Nationally, the First Nation employment rate has risen modestly, as has the national rate among "other" communities. However, at the regional level employment rates have diverged. The 1981-2016 increases in the employment rate are substantial (over 10 percentage points) in the Atlantic region, Quebec, and the Territories. On the other hand, employment since 1981 has stagnated in Manitoba and Saskatchewan, and declined in Alberta.

Prairie communities are dramatically overrepresented in the bottom quarter of results for each CWB sub-index. In Manitoba and Saskatchewan, half of First Nation communities have an employment rate below the national employment bottom quartile; slightly less than half display a housing score below the relevant bottom quartile. Not surprisingly, the income index of more than half of First Nation communities in these two provinces is below the bottom quartile. In Alberta, bottom quarter prevalence of the four indices is (with one exception) lower than in the two other Prairie provinces; prevalence is nonetheless above the national average.

Since the beginning of this century, a major migration from reserve to town has been taking place among those who identify in the Census as First Nation. In the 2001 Census, 45 percent of the First Nation population resided on-reserve, in the 2016 Census only 34 percent. The majority of the First Nation population now live in a city, over a third in a large city (population over 100,000). Why this migration? Probably, the best answers come from the large-scale survey of 2,600 urban Indigenous people (Métis and Inuit, as well as First Nation) undertaken for the Urban Aboriginal Peoples Study:

When asked (unprompted, without response options offered) why they first moved to their city, equal proportions cite the opportunity to be closer to family (38\%), and the pursuit of education (37\%) and employment opportunities (37\%). Smaller proportions say they moved to their city because it offered better amenities (18\%), the chance to escape a bad family situation (10\%) and the opportunity for career advancement (9\%). (Environics 2010, 32.)

This brings us back to the question, what determines employment rates. There is a strong presumption that education levels matter. Higher education levels enable workers to command higher wages, which increase the reward from employment and the willingness to seek a job. Also, higher education levels increase the gap between employment earnings and transfer income available on-reserve. The size of this gap presumably has an impact on the employment rate. In the latest Census, all identity groups—non-Indigenous, Métis, First Nation off-reserve, First Nation on-reserve-experienced an increase of at least 20 percentage points between those with and without high-school certification. With post-secondary certification or university degrees, employment rates for all groups are higher yet, but the major jump in employment is associated with high-school completion (Richards 2018,10-11).

Many factors other than education underlie employment rates-in particular, distance of a First Nation community from an urban labour market. Those living in decent housing may be better able to seek and maintain a job. Hence, the housing index appears to be a relevant factor in explaining the employment rate. Finally, in the spirit of Flanagan's analysis (2019), the housing index may be a proxy for the role of overall community governance in promoting employment.

\section{Policy Implications}

Well governed First Nation communities with access to business opportunities - for example, those with treaty rights relevant to development of resource projects-are realizing employment benefits and higher CWB scores. However, such communities are the minority.

Affirmation of treaties and Indigenous culture over the last quarter 
century has been valuable. That said, for many living in First Nation communities with a low CWB score, out-migration is a reasonable choice-vis. the 2001-2016 migration trend. However, without at least high-school certification, employment and income options are limited both on- and off-reserve. From an intergenerational perspective, better $\mathrm{K}-12$ school outcomes are essential - as is postsecondary training.

Those who definitely want to live in remote communities should be able to do so with reasonable employment prospects. For that to happen, successful out-migration must become more feasible for those wanting to "go to town". At present, those living in First Nation communities with weak education outcomes face limited employment options - whether in their community or "in town". There must be no illusions: realizing significant education improvements in education outcomes among First Nation communities with low CWB scores poses many obstacles.

First is the presence of First Nation mistrust of government interventions intended to improve on-reserve education. Much of this mistrust lies in the abuses associated with residential schools. Those who share this mistrust must acknowledge a dilemma: there is little expertise in either Indigenous Services Canada or among most band councils in the administrative requirements of good schools. Since the expertise in running schools lies primarily in provincial education ministries, inevitably they must be involved.

Second is the need to organize reform while respecting First Nations cultural traditions. First Nations have a constitutional right to organize schools for their children, and most on-reserve children attend an on-reserve primary school under band control. Successful pedagogy in reserve schools should not set low standards for core subjects (reading, math, science), but it must make major adjustments relative to pedagogy in a typical provincial school (Waubageshig [McCue] 2016).

Third is a lack of low-stake assessments of student performance in core subjects among students in on-reserve schools. What assessments do exist often reveal disappointing results. Anderson and Richards (2016) cite evidence on reading assessments in BC reserve schools over the K-12 cycle. The share of children reading "at grade level" declines from approximately 50 percent in early primary to 20 percent by Grade 8 . Similar declines have been found in reserve schools elsewhere.

Fourth is realizing significant improvements will be expensive. Among the most promising initiatives in improving education outcomes among secondary students at high risk of dropout has been Pathways, a NGO that combines extensive tutoring and mentoring of students living in selected low-income urban neighbourhoods. The annual cost per student is approximately $\$ 5,000$. Pathways organized its original project in a public housing project in Toronto. The evaluation of Pathways by Oreopoulus and colleagues (2015) addressed the self-selection bias in such projectsthe difficulty in measuring whether success is due to the initiative or to supportive families whose children are likely to graduate with or without special support.

A final observation: there is no silver bullet to resolve the social problems prevalent in First Nation communities with low CWB scores. Addressing the problems over the next generation will require recognition of First Nation treaty claims over resource-related employment and income, competent First Nation governance of local services, acceptance of out-migration as part of the solutionand higher quality schools.

\section{Endnotes and References}

${ }^{1}$ The employment rate is here defined as those employed, ages 20 64 , relative to the relevant population, ages 20-64. For further detail on substitution of a revised employment rate for the CWB labourforce participation index see the recent C.D. Howe Institute E-Brief (Richards 2020).

${ }^{2}$ Note that these data refer to all Indigenous people and do not
differentiate between on- versus off-reserve location.

For a complete list of references, please refer to the online version of this Policy Brief, found on www.schoolofpublicpolicy.sk.ca.

ISSN 2369-0224 (Print) ISSN 2369-0232 (Online)

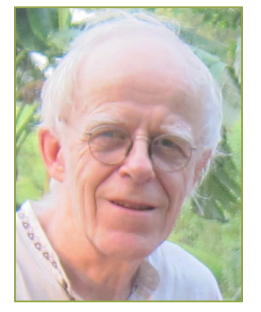

\section{John Richards}

A trained economist, John Richards has written extensively on social policy in Canada, primarily via the C.D. Howe Institute where he holds the Roger Phillips chair in social policy. His current social policy focus is on Aboriginal policy. He is also the co-editor of Inroads, a Canadian policy journal. A professor at Simon Fraser University's School of Public Policy, Richards has taught and conducted research in Bangladesh over the last decade and heads a modest policy institute linked to the International University of Business Agriculture and Technology.

People who are passionate about public policy know that the Province of Saskatchewan has pioneered some of Canada's major policy innovations. The two distinguished public servants after whom the school is named, Albert W. Johnson and Thomas K. Shoyama, used their practical and theoretical knowledge to challenge existing policies and practices, as well as to explore new policies and organizational forms. Earning the label, "the Greatest Generation," they and their colleagues became part of a group of modernizers who san government as a positive catalyst of change in post-war Canada. They created a legacy of achievement in public administration and professionalism in public service that remains a continuing inspiration for public servants in Saskatchewan and across the country. The Johnson Shoyama Graduate School of Public Policy is proud to carry on the tradition by educating students interested in and devoted to advancing public value. 